\title{
Cyclic consolidation and axial friction for seabed pipelines
}

\author{
Y. YAN*, D. J. WHITE* and M. F. RANDOLPH*
}

\begin{abstract}
Finite-element analyses of the axial sliding resistance of a seabed pipeline embedded in soft normally consolidated modified Cam clay are presented. The study demonstrates the rise in axial resistance associated with episodes of movement with intervening periods of consolidation. It is shown that the excess pore pressures generated during undrained axial movements lead to significant consolidation and strength gain in the surrounding soil. For modified Cam clay, using properties representative of kaolin, the resistance rises exponentially with cycles and reaches the drained limit within approximately 10-20 episodes of movement and consolidation. The rate of gain in resistance is shown to be controlled by the volumetric stiffness ratio, $\kappa / \lambda$, for soil that is initially normally consolidated. Simple relationships are proposed that will assist in utilising this beneficial phenomenon in design practice. The increase in axial sliding resistance due to consolidation may mean that mitigation requirements against cyclic axial pipe walking, caused by thermal expansion, may be reduced or eliminated.
\end{abstract}

KEYWORDS: consolidation; numerical modelling; offshore engineering; pipelines

ICE Publishing: all rights reserved

\section{INTRODUCTION}

Pipe 'walking' is the unwanted accumulation of axial movement of a seabed pipeline during cycles of operation. This is an increasingly significant design challenge as operating pressures and temperatures rise for pipelines on soft fine-grained soils. The rate at which a pipeline will axially 'walk' during cycles of startup and shutdown is strongly influenced by the axial pipe-soil sliding resistance.

The first comprehensive study of pipe walking was reported by Tornes et al. (2000) and analytical solutions linking pipe-soil friction and pipe walking rate for simple scenarios were presented by Carr et al. (2006). A significant quantity of experimental data on axial pipe-soil resistance was collated by White et al. (2011), showing the influence of drainage and excess pore pressure. White \& Cathie (2011) set out a framework for axial pipe-soil resistance based on an effective stress approach, spanning both undrained and drained conditions. It was proposed that the axial resistance during cycles of pipeline movement will tend towards the drained value, regardless of the rate or duration of each movement event, because the soil surrounding the pipe will eventually consolidate to a critical state at which excess pore pressure generation will not occur. There is a significant design benefit if this mechanism can be reliably predicted, since the drained resistance is typically higher than the undrained resistance. A narrower and higher design range of axial friction leads to less onerous walking mitigation measures such as reduced anchoring requirements.

To capture this mechanism, a quantitative analytical framework based on planar shearing with concurrent drainage and consolidation was introduced by Randolph et al. (2012), using critical state theory. This solution describes the transition from undrained to drained axial

Manuscript received 27 April 2014; first decision 29 May 2014; accepted 9 June 2014.

Published online at www.geotechniqueletters.com on 14 July 2014.

${ }^{*}$ Centre for Offshore Foundation Systems, University of Western Australia, Crawley, WA, Australia pipe-soil resistance due to consolidation concurrent with pipe movement. The results were validated for a curved geometry of a pipeline by finite-element analyses of axial pipe-seabed interaction with coupled consolidation, and these results are described further by Yan (2014). This paper extends the previous work to the situation in which consolidation occurs between pipe movement events, which are themselves undrained. This situation represents typical pipeline operating behaviour on soft marine clays. The pipe moves axially during the process of starting up or shutting down the pipeline. During the intervening period when the pipe is either in operation or is shut down, any excess pore pressure in the surrounding soil dissipates, causing a change in strength and therefore sliding resistance during the subsequent axial movement.

\section{FINITE-ELEMENT METHODOLOGY}

Three-dimensional coupled small-strain finite-element analyses have been undertaken using the modified Cam clay soil model (Roscoe \& Burland, 1968), as implemented in Abaqus. An infinite length of pipe was modelled by a narrow prism of elements, constrained so the nodes on the vertical planes confining the prism moved identically, as described by Randolph et al. (2012). The pipe was modelled as a $0.5 \mathrm{~m}$ diameter rigid circular body with a fully rough surface, pre-embedded to a depth of 0.3 diameters. The embedded pipe nodes were tied to the adjacent soil elements.

The soil was defined as a linear elastic-plastic material. All parameters adopted in the numerical analyses are listed in Table 1 . The soil body was initially consolidated with $K_{0}=0.6$ and an artificial $0.001 \mathrm{kPa}$ surcharge on the top surface to provide computational stability. These initial conditions cause the strength and other properties (in particular the initial $c_{\mathrm{v}}$ and $e$ ) to vary with depth, following standard relationships (Wroth, 1984). A fine mesh was assigned close to the pipe, reducing to an element size of $0.002 D$ at the pipe-soil interface to eliminate mesh density effects. Further details of the adopted modified Cam clay soil model and finite-element modelling methods used in 
Table 1. Input parameters of numerical study

\begin{tabular}{l|c}
\hline Soil property/parameter & Value \\
\hline Slope of critical state line in $p^{\prime}-q$ space, $M$ & $0 \cdot 92$ \\
Friction angle in triaxial compression, $\phi^{\prime}$ tc & $23 \cdot 5^{\circ}$ \\
Void ratio at $p^{\prime}=1 \mathrm{kPa}$ on critical state line, & $2 \cdot 14$ \\
$e_{\mathrm{cs}}$ & $0 \cdot 205$ \\
Slope of virgin compression line in $e-\ln \left(p^{\prime}\right)$ & \\
space, $\lambda$ & $0 \cdot 044$ \\
Slope of swelling and recompression line in & \\
$e-\ln \left(p^{\prime}\right)$ space, $\kappa$ & $50 p^{\prime} 0$ \\
Elastic shear modulus, $G$ & $15 \cdot 0$ \\
Saturated bulk unit weight, $\gamma_{\text {sat }}: \mathrm{kN} / \mathrm{m}^{3}$ & 10 \\
Unit weight of water, $\gamma_{\mathrm{w}}: \mathrm{kN} / \mathrm{m}^{3}$ & $1 \cdot 0 \times 10^{-9}$ \\
Permeability of soil, $k: \mathrm{m} / \mathrm{s}$ & $9 \cdot 25 \times 10^{-10}$ \\
Consolidation coefficient at pipe invert, $c_{\mathrm{v} 0}:$ & $0 \cdot 5$ \\
$\mathrm{~m}^{2} / \mathrm{s}$ & \\
Pipe diameter, $D: \mathrm{m}$ & \\
\hline
\end{tabular}

the present study are described by Chatterjee et al. (2012), Randolph et al. (2012) and Yan (2014). Dimensionless values of time $T_{\mathrm{v}}=c_{\mathrm{v} 0} t / D^{2}$, and velocity, $V=v D / c_{\mathrm{v} 0}$, were assessed using the initial $c_{\mathrm{v} 0}$ value at the depth of the pipe invert $(0 \cdot 15 \mathrm{~m})$. This value was derived using the initial soil state and plastic isotropic compressibility $\left(m_{v}=\right.$ $\lambda\left(1+e_{0}\right) / p_{0}^{\prime}$ and is shown in Table 1 .

\section{ANALYSIS PROCEDURES}

The analyses involved firstly applying a simulated weight of the pipeline equal to the ultimate vertical bearing capacity $(V / D \approx 1.7 \mathrm{kPa})$ at the adopted pipe invert embedment of $0 \cdot 3 D$. This vertical load was applied for a period sufficient for full dissipation of the excess pore pressure created by the pipe weight and was then maintained constant for the remainder of the analysis. The pipe was then subjected to the following different sliding episodes.

- Single sliding events - undrained and drained at failure. The pipe was subjected to continuous axial movement with constant velocities of $v D / c_{\mathrm{v} 0}=2000$ (undrained failure) and $0 \cdot 2$ (drained failure) for a sufficient sliding distance to identify the fully drained resistance. These two cases have been reported elsewhere (Randolph et al., 2012; Yan, 2014). The undrained failure case forms the fundamental 'backbone' curve for concurrent sliding and consolidation in which failure is reached prior to any significant pore pressure dissipation. After failure, the resistance rises progressively from the undrained limit to the drained limit. In the drained case, dissipation occurs more rapidly than the mobilisation of the sliding resistance, which only reaches a plateau at the drained limit.

- Cyclic sliding event - undrained at failure. The pipe was subjected to a series of undrained sliding events, with intervening periods of full excess pore pressure dissipation, to represent typical operational conditions. The movements were at a velocity of $v D / c_{\mathrm{v} 0}=2000$ over a sufficient distance for the undrained resistance to be fully mobilised, without significant excess pore pressure dissipation. Twenty cycles of movement and consolidation were simulated. The base case cyclic sliding analysis used the parameters given in Table 1 and two additional cases used alternative values of $\lambda$ and $\kappa$, as discussed later.

\section{RESULTS}

\section{Sliding resistance and pore pressure dissipation}

The base case cyclic sliding analysis showed an increase in axial pipe-soil resistance consistent with the cyclic

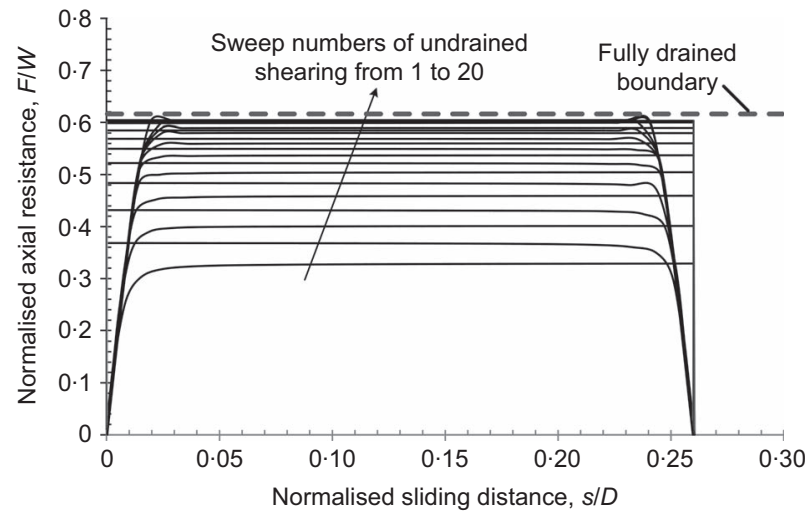

Fig. 1. Axial sliding resistance-displacement responses for general pipe walking

hardening mechanism proposed by White \& Cathie (2011). The equivalent axial friction factor during the initial movement is 0.32 , which is consistent with the normally consolidated strength ratio of the soil, enhanced slightly by wedging around the pipe periphery (White \& Randolph, 2007). After 20 cycles, the resistance has risen close to the drained limit given by an interface friction of $\tan \phi$ (Fig. 1), which is consistent with model test observations (Smith \& White, 2014).

The changes in excess pore pressure are described by the normalised quantity $r_{\mathrm{u}}=\left(\Delta u_{\mathrm{av}} / \sigma_{\mathrm{Nav}}\right)$, where $\Delta u_{\mathrm{av}}$ is the excess pore pressure and $\sigma_{\mathrm{Nav}}$ is the normal pipe-soil stress, averaged around the pipe-soil interface. The rise and fall in $r_{\mathrm{u}}$ with each episode of sliding and reconsolidation is shown in Fig. 2, with the dimensionless time reset at the start of each movement. Higher excess pore pressure is generated in the early sweeps, consistent with the lower sliding resistance. The normalised dissipation response is fitted approximately by the relationship

$$
\frac{\Delta u_{\mathrm{av}}}{\Delta u_{\mathrm{av}, i}}=\frac{1}{1+\left(T_{\mathrm{v}} / T_{50}\right)^{m}}
$$

where $T_{50}$ is the value of $T_{\mathrm{v}}$ for $50 \%$ dissipation and $m$ is a constant (see Fig. 3 and Table 2). $T_{50}$ decreases during the first few episodes and remains stable at $T_{50} \approx 0.004$ from sweep 8 onwards. Consolidation is practically complete by $T_{\mathrm{v}} \approx 0 \cdot 3$.

The intermittent sliding case is compared with the monotonic fast and slow sliding cases in Fig. 4, without

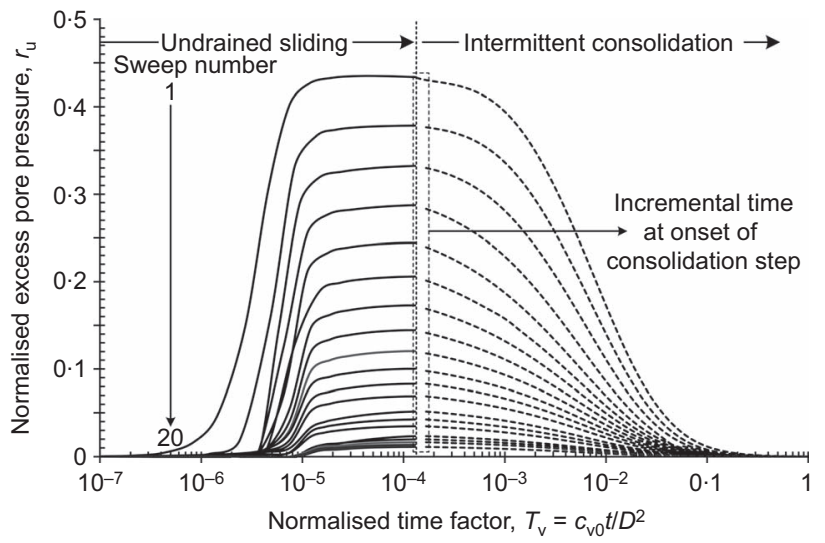

Fig. 2. Excess pore pressure responses during general pipe walking 


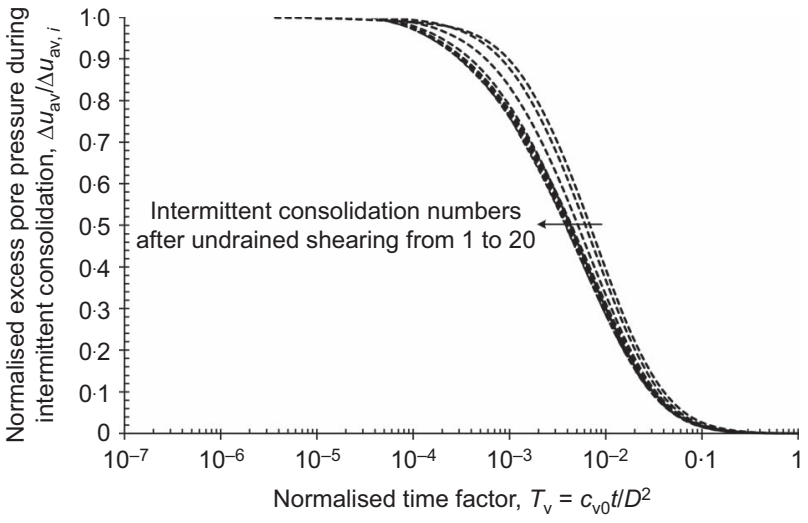

Fig. 3. Normalised excess pore pressure responses after each undrained sweep

'resetting' the time axis to zero at the start of each intermittent sweep. The fast monotonic sliding case shows the undrained-drained backbone response for continuous shearing, as analysed previously by Randolph et al. (2012). This response provides benchmark values of the fully undrained and fully drained sliding resistance, with the latter value being reached at a dimensionless time of $T_{\mathrm{v}} \approx$ 1. The slow monotonic case confirms the drained sliding resistance, and reaches this value slightly later. The intermittent cyclic sliding case reaches the same drained resistance limit, but after a cumulative time of $T_{\mathrm{v}} \approx 5$, and 20 pipe movement events totalling only $T_{\mathrm{v}} \approx 10^{-4}$ in duration.

To predict the rate of hardening for intermittent cyclic sliding, it is clearly necessary to consider the accumulated cycles of shearing and dissipation rather than the cumulative movement time or the overall elapsed time.

\section{Cyclic evolution of sliding resistance}

The measured variation in sliding resistance is shown in Fig. 5 in a normalised manner as the drainage index $\Psi$, which varies from 0 to 1 as the current resistance $(F / W)$ rises from the initial undrained limit $(F / W)_{\text {undrained to the }}$ drained limit $(F / W)_{\text {drained }}$

$$
\Psi=\frac{(F / W)-(F / W)_{\text {undrained }}}{(F / W)_{\text {drained }}-(F / W)_{\text {undrained }}}
$$

The resistance mobilised during sweep $n$ can be fitted by the simple power law

$$
\Psi=1-\exp \left[-0 \cdot 7(n-1) / N_{50}\right]
$$

in which $N_{50}$ is the number of cycles of movement and consolidation required to achieve $50 \%$ of the full hardening process, or a drainage index of $\Psi=0 \cdot 5$. As shown by the stress paths discussed later, the hardening effect depends on the reduction in moisture content. The final reduction in

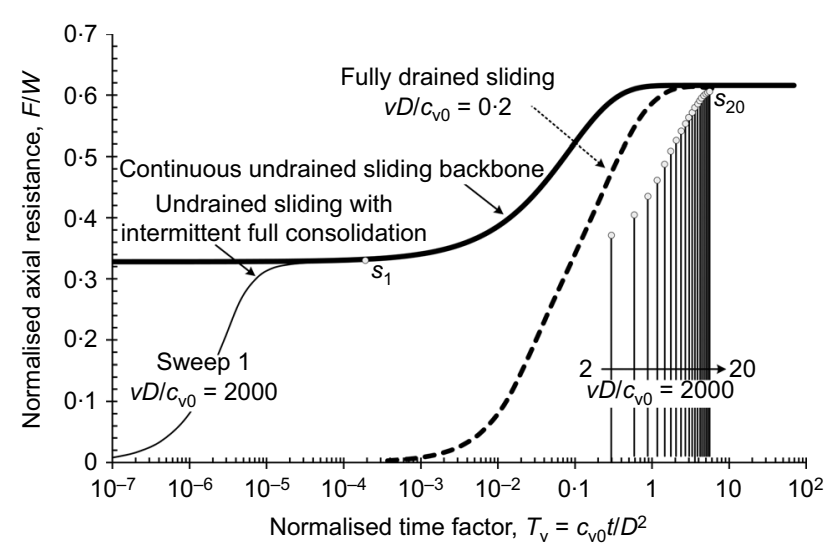

Fig. 4. Consolidation curves for general pipe walking

moisture content depends on the steepness of the critical state line $\lambda$, while the reduction during each reconsolidation event depends on the unload-reload gradient $\kappa$. There is therefore a dependency of $N_{50}$ on the ratio $\kappa / \lambda$ (or alternatively the volumetric strain ratio $\Lambda=1-\kappa / \lambda)$, which is illustrated by the results from two additional cyclic analysis cases shown in Fig. 5. By doubling $\kappa$ or halving $\lambda$, the rate of hardening is doubled.

A simple relationship to capture this effect is

$$
N_{50}=\frac{0 \cdot 9}{\kappa / \lambda}
$$

which leads to the two fitted curves shown in Fig. 5 that show good agreement with the numerical results.

Equations (3) and (4) require extension to cover cases in which the soil is initially over-consolidated and the cyclic hardening rate will depend on other aspects of the soil model, such as the spacing ratio between the normal compression and critical state lines. The ratio $\kappa / \lambda$ alone is unlikely to capture all aspects of the cyclic hardening in natural soils, particularly when there is significant structure.

\section{Stress paths beneath a pipe invert}

The effective stress and stress:volume paths followed by a soil element located immediately beneath the pipe invert are shown in Figs 6(a) and 6(b), respectively. During initial loading of the pipe, the effective stress reduces as the stress path moves to the failure line. The effective stress then rises during the subsequent pore pressure dissipation, while the voids ratio reduces. During subsequent cycles of sliding and consolidation, the stress path follows a zig-zag pattern in stress:volume space with successive generation and dissipation of excess pore pressure. As the voids ratio approaches the critical state value for the stress imposed by the pipe, the level of excess pore pressure generation diminishes and the asymptotic condition in which drained and

Table 2. Values of $T_{50}$ and constant $m$ for equation (1)

\begin{tabular}{l|l|l|l|l|l|l|c|c}
\hline & \multicolumn{9}{c}{ Pipe sweep number } \\
\cline { 2 - 8 } & 1 & 2 & 3 & 4 & 5 & 6 & 7 \\
\hline$m$ & $1 \cdot 20$ & $1 \cdot 15$ & $1 \cdot 10$ & $0 \cdot 95$ & $0 \cdot 94$ & $0 \cdot 90$ & $0 \cdot 90$ \\
$T_{50}$ & $0 \cdot 0065$ & $0 \cdot 0060$ & $0 \cdot 0050$ & $0 \cdot 0044$ & $0 \cdot 0043$ & $0 \cdot 0042$ & $0 \cdot 0042$ \\
\hline
\end{tabular}




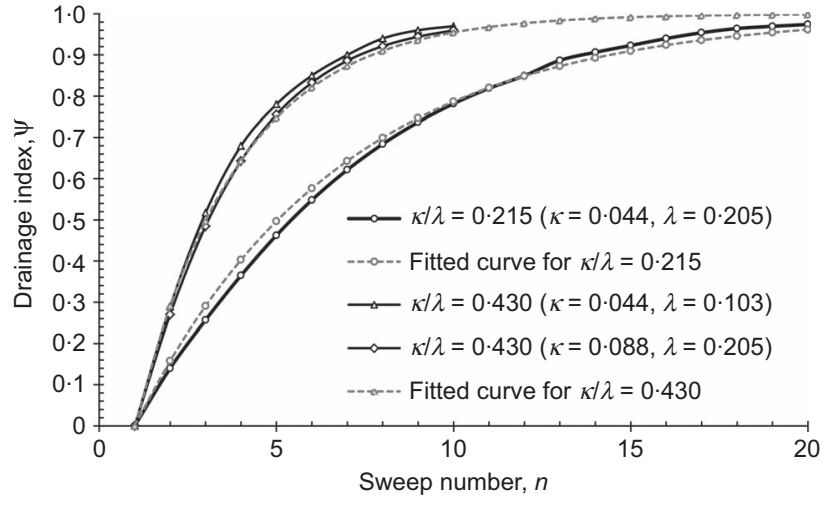

Fig. 5. Gain in axial resistance with sweep number

undrained sliding resistances are equal is approached. This causes the stress path in $p^{\prime}: q$ space to become vertical.

Figure 6 also shows the stress path during the slow monotonic drained sliding case, which reaches the same ultimate state.

\section{Strength changes beneath pipe invert}

The cycles of shearing and consolidation cause a reduction in voids ratio and an increase in shear strength over a zone that extends well beyond the pipe invert. Figure 7 shows the increases in soil strength down a profile directly below the pipe invert. The soil strength profile is initially proportional to depth, with a value of $s_{\mathrm{u}} \approx 0.2 \mathrm{kPa}$ at the pipe invert level. After consolidation under the vertical pipe load, this strength rises to $\approx 0.5 \mathrm{kPa}$, but the cycles of sliding and consolidation create a far greater rise in shear strength to an ultimate value of $\approx 1 \cdot 2 \mathrm{kPa}$. This variation in undrained strength is consistent with the rise in sliding resistance. The zone of significant strength gain extends $\approx 0.5 D$ beneath the pipe invert, which is consistent with experimental observations from model tests of axial pipesoil interaction (Smith \& White, 2014).

\section{CONCLUSIONS}

It has been hypothesised that the axial sliding resistance between a pipe and the seabed on soft normally consolidated clay will rise from the initial undrained value to

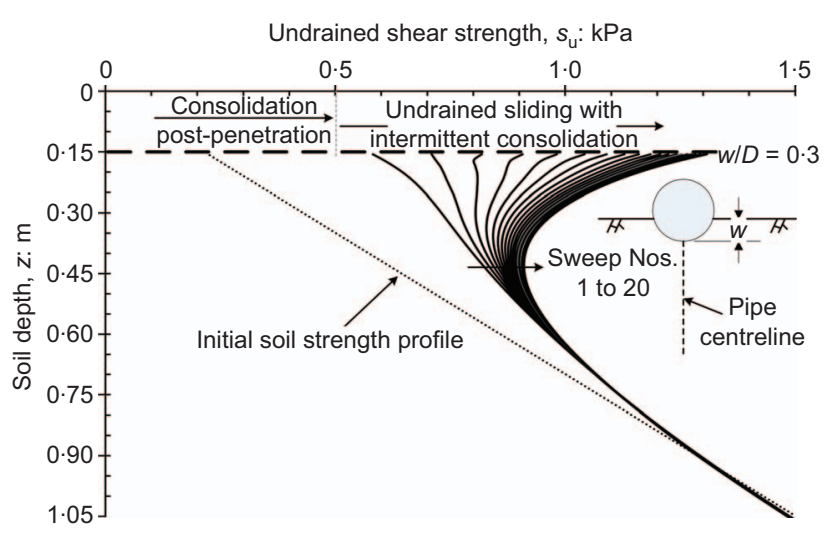

Fig. 7. Profiles of shear strength during and after general pipe walking

the drained limit, with a consequential benefit of reduced cyclic axial movement or 'walking'. This effect has previously been analysed for the case of continuous sliding with concurrent consolidation. This paper provides the first theoretical quantification of this effect for episodic sliding, which comprises undrained movements interspersed with full consolidation.

It is shown that, for modified Cam clay, using properties representative of kaolin, the resistance rises exponentially with number of cycles and reaches the drained limit within approximately 20 episodes of movement and consolidation. The rise in resistance is accompanied by a corresponding increase in the strength of the soil surrounding the pipe.

The process of episodic shearing and intervening full consolidation means that the rate of gain in resistance is not dependent on the coefficient of consolidation of the soil, but varies with cycle number at a rate that depends on the ratio $\kappa / \lambda$.

\section{ACKNOWLEDGEMENTS}

The work described in this paper forms part of activities at the Centre for Offshore Foundation Systems (COFS) at the University of Western Australia, currently supported as a node of the Australian Research Council Centre of Excellence for Geotechnical Science and Engineering. The second author is supported by Shell Australia, via the Shell EMI Chair of Offshore Engineering.

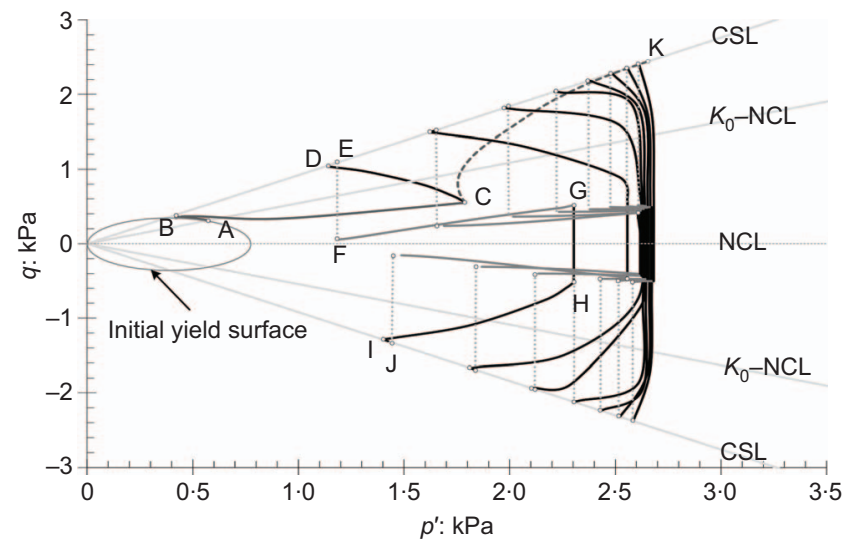

(a)

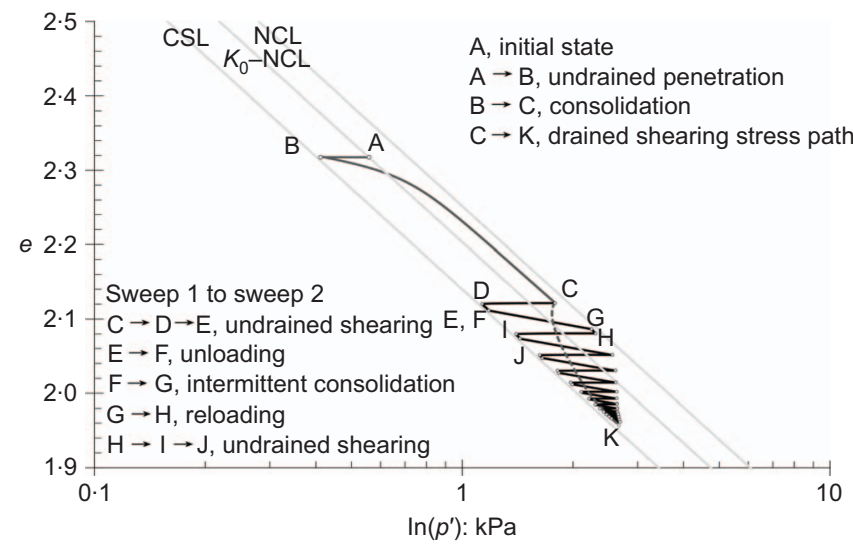

(b)

Fig. 6. Response of soil element beneath pipe invert: (a) stress path; (b) stress : volume path. NCL = normal compression line; $\mathrm{CSL}=$ critical state line 


\section{REFERENCES}

Carr, M., Sinclair, F. \& Bruton, D. (2006). Pipeline walking understanding the field layout challenges, and analytical solutions developed for the SAFEBUCK JIP. Proc. Offshore Technology Conference, Houston, TX, paper OTC17945.

Chatterjee, S., Yan, Y., Randolph, M. F. \& White, D. J. (2012). Elastoplastic consolidation beneath shallowly embedded offshore pipelines. Géotech. Lett. 2, No. 2, 73-79.

Randolph, M. F., White, D. J. \& Yan, Y. (2012). Modelling the axial soil resistance on deepwater pipelines. Géotechnique 62, No. 9, 837-846.

Roscoe, K. H. \& Burland, J. B. (1968). On the generalised stressstrain behaviour of 'wet clay'. In Engineering plasticity (Heyman, J. \& Leckie, F. A. (eds)). Cambridge: Cambridge University Press, pp. 535-609.

Smith, V. B. \& White, D. J. (2014). Volumetric hardening in pipesoil interaction. Proc. Offshore Technology Conference, Kuala Lumpur, paper OTC24856MS.

Tornes, K., Jury, J. \& Ose, B. (2000). Axial creeping of high temperature flowlines caused by soil racheting. Proc. ASME Conf. on Offshore Mechanics and Arctic Engineering, New Orleans, USA, paper OMAE-PIPE5055.

White, D. J. \& Cathie, D. N. (2011). Geotechnics for subsea pipelines. Proc. 2nd Int. Symp. on Frontiers in Offshore Geotechnics, Perth, pp. 87-123.

White, D. J. \& Randolph, M. F. (2007). Seabed characterisation and models for pipeline-soil interaction. Int. J. Offshore Polar Engng 17, No. 3, 193-204.

White, D. J., Bolton, M. D., Ganesan, S. A., Bruton, D., Ballard, J.-C. \& Langford, T. (2011). SAFEBUCK JIP: Observations from model testing of axial pipe-soil interaction on soft natural clays. Proc. Offshore Technology Conference, Houston, $T X$, paper OTC21249.

Wroth, C. P. (1984). The interpretation of in-situ tests: 24th Rankine lecture. Géotechnique 34, No. 4, 449-489.

Yan, Y. (2014). Novel methods for characterising pipe-soil interaction forces in situ in deep water. $\mathrm{PhD}$ thesis, University of Western Australia.

\section{WHAT DO YOU THINK?}

To discuss this paper, please email up to 500 words to the editor at journals@ice.org.uk. Your contribution will be forwarded to the author(s) for a reply and, if considered appropriate by the editorial panel, will be published as a discussion. 